\title{
Les opinions politiques d'un avocat parisien sous Henri IV: Antoine Arnauld
}

\author{
MICHEL DE WAELE
}

\section{$\mathrm{R}$}

ésumé: Antoine Arnauld est surtout connu des historiens pour ses attaques virulentes contre les Jésuites. Mais cet avocat parisien a participé à tous les débats qui secouèrent la France durant le règne d'Henri IV. Royaliste convaincu, ardent défenseur des privilèges du parlement, ses opinions politiques reflètent les positions des nombreux robins qui, tout en s'inquiétant des tendances centralisatrices du roi et de certains de ses conseillers, souhaitaient voir le monarque et la monarchie respectés de nouveau par l'ensemble des Français après trente ans de guerres civiles.

Le 12 juillet 1594, Antoine Arnauld prononce dans l'enceinte du parlement parisien un vibrant plaidoyer en faveur de l'Université de Paris dans le cadre du procès opposant cette institution à la Société de Jésus. Cette harangue eut un retentissement énorme, devenant "avec les Lettres Provinciales, une des sources qui ont fourni le plus d'arguments aux ennemis de la Compagnie."I

Le succès de ce discours eut cependant un effet néfaste sur son auteur. En effet, les historiens ont "oublié" d'étudier les autres facettes du personnage, ne retenant de lui que ses prises de position contre les Jésuites. ${ }^{2}$ Ses enfants, qui deviendront d'ardents défenseurs du jansénisme en France, retiennent davantage l'attention des chercheurs. Sa fille, la mère Marie-Angélique, réformera l'abbaye de Port-Royal; son fils, le "Grand Arnauld" publiera de nombreux traités défendant la pensée janséniste. ${ }^{3}$ S'agit-il là pourtant des seuls points d'intérêt de cet avocat?

Arnauld, il est vrai, n'est pas à proprement parler un "penseur" politique.. Il ne développe pas de théories personnelles sur les sujets faisant l'objet de débats en France à la fin des guerres de religion. Il intervient cependant dans plusieurs controverses qui secouent le royaume au tournant du XVII ${ }^{\mathrm{e}}$ siècle: les relations entre nobles de robe et nobles d'épée, le gallicanisme, le gouvernement en général, le développement économique de la France. A une époque où près de la moitié des magistrats sont les premiers de leur famille à siéger 
au sein du parlement et n'ont pas grandi au sein de la "République des Lettres," composée par les anciennes familles de robe, gardiennes des traditions parlementaires, Arnauld défendra toujours avec virulence les coutumes et privilèges de cette institution à l'intérieur du royaume. Cette position mérite d'être examinée en détail, car, malgré tout le respect manifesté par Arnauld pour le roi et pour la monarchie, elle se traduira par une opposition à Henri IV durant la première partie de son règne.

Le cheminement politique d'Antoine Arnauld nous éclaire sur les agissements d'un certain nombre de parlementaires qui, fidèles au Béarnais durant les guerres de religion, s'opposeront presque conscientieusement à celui-ci après la reconquête du royaume par le roi. Soucieux de la stabilité de la France et du bien-être des Français, ces juristes lui reprocheront de ne pas s'occuper assez de ses sujets et de ne pas respecter les traditions qui avaient assuré jadis la grandeur de la nation. Arnauld n'a certes pas l'influence ou la réputation d'un Achille de Harlay, premier président du parlement de Paris, d'un Jacques Auguste de Thou, président à mortier ou de ses collègues avocats Étienne Pasquier et Antoine Loisel. Toutefois, l'étude de ses écrits montre que les idées défendues par les grands parlementaires traditionnalistes trouvent des échos favorables parmi les avocats du parlement, que la division du monde judiciaire parisien au tournant du XVII ${ }^{\mathrm{e}}$ siècle affecte l'ensemble du corps judiciaire.

$* \quad * \quad *$

Antoine Arnauld est baptisé le 6 août 1560 en l'église Saint André des Arts, à Paris. Son père, bien que fidèle à la foi protestante, préféra, comme bon nombre de ses contemporains favorables à la Réforme, faire baptiser ses enfants. L'éducation première du jeune Arnauld se déroule ainsi dans la religion réformée, la famille se convertissant au catholicisme après la SaintBarthélémy. Arnauld étudie ensuite au Collège de Navarre où il est reçu très jeune maître ès arts.

Avocat au parlement de Paris, Arnauld se fait rapidement remarquer de ses collègues par son éloquence. Il succède à son père comme procureur général de Catherine de Médicis et occupe également une charge d'auditeur des comptes, charge qu'il abandonne rapidement pour se consacrer uniquement au barreau.

Le patriotisme d'Arnauld, un des traits majeurs de son caractère, éclate au grand jour dans quatre pamphlets, écrits alors que Paris se trouve aux mains des catholiques extrémistes de la Ligue. ${ }^{4} \mathrm{Ce}$ sentiment national intense, qui se manifeste dès les premiers écrits, se retrouvera dans toutes ses oeuvres. 
Quatre notions retiennent particulièrement son attention: le roi et le royaume; la France et les Français; l'histoire nationale; et l'Église gallicane. Il ne fait jamais mention de la langue française, pourtant l'un des éléments majeurs de la conscience nationale durant la deuxième moitié $\mathrm{du} \mathrm{XVI}^{\mathrm{e}}$ siècle. La langue française, comme symbole de la conscience nationale, se manifesta surtout pour contrer la prédominance de l'italien. Les pamphlétaires royalistes n'insistent jamais sur le danger de voir l'espagnol supplanter le français en cas de victoire de la Ligue. ${ }^{5}$

Dans ses quatre premiers textes, Arnauld dénonce l'ingérence de l'Espagne dans les affaires françaises. Il tente également de regrouper ses concitoyens autour du roi légitime en mettant de l'avant, en accord avec la politique royale de réconciliation nationale, toute une série de concepts tels que la France, la patrie, l'État, la monarchie. Ces écrits jouiront d'un certain succès: en effet, rapidement traduit en anglais et distribué outre-Manche, L'Anti-Espagnol sera republié en France en 1592 et en 1594.

L'année 1594 marque un tournant important dans la vie d'Arnauld. Choisi par l'Université de Paris pour la représenter dans le procès l'opposant aux Jésuites, il livre, le 12 juillet, un plaidoyer qui ne laisse personne indifférent. ${ }^{6}$ Encore imprégné du caractère impétueux du pamphlétaire, Arnauld se laisse emporter par sa passion jusqu'à l'aveuglement. La calomnie tient une place importante dans ses propos, ce que lui reprocheront un certain nombre de ses contemporains, dont le chroniqueur Pierre de l'Étoile, pourtant peu sympathique aux Jésuites. ${ }^{7}$

Son patriotisme inspirera à Arnauld deux autres textes. En 1598, Henri IV contrôle la majeure partie de son royaume. Seule la Bretagne, tenue par le duc de Mercoeur, lui résiste encore. Arnauld publie alors un texte dans lequel il soutient les entreprises royales contre la province et le duc rebelles. En 1600, alors que la France et la Savoie sont aux prises au sujet du marquisat de Saluces, Arnauld dénonce la politique ambitieuse de la maison savoyarde. ${ }^{8}$

Arnauld aborde une nouvelle phase de sa carrière en 1602. Chassée de France après l'attentat commis par Jean Chastel contre le roi le 27 décembre 1594, la Compagnie de Jésus entreprend au début du XVII ${ }^{\mathrm{e}}$ siècle des négociations en vue de son rétablissement dans le royaume. Celles-ci irritent au plus haut point Arnauld qui s'élève contre l'éventuel retour de la Société en France. ${ }^{9}$ Mais, ayant été bannie par un arrêt du parlement, la Société de Jésus ne peut être réintégrée par Henri IV sans contrevenir à un décret de sa cour souveraine.

$\mathrm{Ne}$ se contentant plus de discourir contre les "méfaits" des Jésuites, Arnauld amorce une réflexion sur la place et les pouvoirs du souverain et du 
parlement au sein de l'appareil gouvernemental. Son attachement pour la monarchie l'avait tenu éloigné des nombreux débats qui avaient éclaté sur la nature du gouvernement pendant les guerres de religion. Mais, faisant partie de la lignée plus "traditionnaliste" des parlementaires, il défend avec acharnement les anciens privilèges de l'institution lorsque ceux-ci se trouvent menacés.

L'attitude d'Henri IV et de certains de ses conseillers qui, tel Sully, veulent cantonner le parlement dans son rôle strictement juridique, a de quoi faire réfléchir Arnauld. De plus en plus, le pouvoir central emploie des intendants et des commissaires pour accomplir des tâches jadis dévolues aux parlementaires. Le développement de la vénalité des offices affecte la position sociale, économique et politique de ces hommes à l'intérieur du royaume. C'est donc un cri d'alarme que lance Arnauld en 1608: plus personne ne respecte la justice, plus personne ne considère la vertu et le mérite; seule importe maintenant la richesse. ${ }^{10}$

Arnauld publiera un dernier texte adressé cette fois à Louis XIII, dans lequel il reprend ses critiques au sujet de la vénalité des offices, affirmant là qu'il s'agit du principal danger menaçant la France. Cette dernière, toutefois, doit également prendre garde aux duels qui minent les rangs de la noblesse, au déficit commercial enregistré avec l'Espagne, et à la faiblesse de sa marine. ${ }^{11}$

Cinq ans plus tard, en décembre 1619, Antoine Arnauld s'éteint, laissant à ses enfants une fortune considérable. A une époque où la chasse aux offices était monnaie courante au sein de la noblesse de robe, il a préféré conserver sa position d'avocat, refusant de nombreux postes offerts par les grands du royaume. Ce comportement s'oppose sur bien des points à celui de certains de ses collègues, de nouveaux pourvus notamment, pour qui la profession judiciaire constitue un investissement ou une simple étape dans la progression sociale ou politique. Pour Arnauld, elle représente davantage un devoir sacré, rempli de responsabilités. ${ }^{12}$

$*$

Le sentiment nationaliste intense chez Arnauld, son attachement profond à la monarchie, l'amènent, pendant les guerres de religion, à se rallier au parti des Politiques. Ceux-ci sont prêts à reconnaître comme leur souverain le protestant Henri de Navarre, pour peu qu'il se convertisse au catholicisme. Le Béarnais, suite à l'assassinat du roi Henri III le $1^{\text {er }}$ août 1589 , devient le titulaire légitime de la couronne selon les règles établies par la loi salique. 
Le nouveau roi a fort à faire pour reconquérir son royaume. Il ne contrôle qu'un sixième de celui-ci au moment de son accession. Hérétique relaps, excommunié par le pape, Henri IV promet dès son arrivée sur le trône de ne pas toucher à la religion catholique et de convoquer un concile pour régler la querelle religieuse. Il se convertit au catholicisme en juillet 1593. Il achète la fidélité de la plupart des chefs ligueurs, consentant à débourser des sommes énormes. Il pardonne à ses anciens ennemis leur rébellion, n'exilant (bien souvent temporairement) que quelques dizaines d'entre eux à la fin des guerres civiles. Lorsque ses armées capturent une ville, il interdit à quiconque, en commençant par ses propres procureurs, de revenir sur les événements passés. Il garantit à la ville et à ses habitants le maintien de leurs anciens privilèges. Il tente de regrouper ses sujets autour d'un objectif commun en déclarant la guerre à l'Espagne le 17 janvier 1595. En 1598, il proclame l'Édit de Nantes par lequel il espère voir la paix religieuse revenir dans le royaume. Finalement, en adoptant une politique mercantiliste, il tente de développer l'économie nationale.

Les robins ont l'impression d'avoir grandement contribué aux succès d'Henri IV. De fait, dans la guerre de propagande qui opposait le parti royal et la Ligue dans la dernière phase des guerres de religion, le roi a pu compter sur l'appui de nombreux juristes qui écrivaient, souvent sur commande, des textes dénonçant l'action des ligueurs et de leurs alliés espagnols. De plus, la majorité des parlementaires parisiens suivent le roi dans son exil à Tours de 1589 à 1594. Leurs collègues restés à Paris, alors que les catholiques zélés contrôlent la capitale, contribuent à leur façon à la victoire du Béarnais. Ils s'opposent aux prétentions extrémistes de la Ligue et distillent tranquillement le crédo royaliste dans l'esprit des opposants au Béarnais. ${ }^{13}$

Mais plus encore, les parlementaires croient que ce dernier leur doit presque directement son trône. En 1593, les États-Généraux ligueurs s'assemblent à Paris pour élire un roi. Le Cardinal de Bourbon, que les ligueurs avaient reconnu comme tel sous le nom de Charles X, était mort en mai 1590. Personne n'avait été désigné pour le remplacer. Ce projet ne peut toutefois être mené à terme. Un arrêt du parlement de Paris qui, épuré par la Ligue, était resté jusque là à peu près fidèle à la cause catholique, confirme le droit inaliénable d'Henri IV à la couronne en rappelant la prédominance de la loi salique. Le roi, sa légitimité confirmée, peut donc compléter la reconquête de son royaume. Les parlementaires rappelleront fréquemment cet épisode pour justifier la place qu'ils désirent occuper au sein du gouvernement national. ${ }^{14}$

Antoine Arnauld met pour sa part sa plume au service d'Henri IV. Il sera l'un des pamphlétaires les plus virulents de l'époque, s'acharnant sur les 
Espagnols, accusés de vouloir s'emparer de la couronne française. Au temps des guerres de religion, les Espagnols jouissent d'une très mauvaise réputation en Europe. ${ }^{15}$ Dès le milieu du $\mathrm{XV}^{\mathrm{e}}$ siècle, les ambassadeurs italiens en poste dans la péninsule ibérique propagent, dans leurs Relations, l'image d'un peuple peu industrieux, grossier, orgueilleux, rusé, pauvre et avare. Ils soupçonnent le sang espagnol d'être fortement teinté de couleur juive ou maure. L'expansion de la puissance de Madrid tout au cours du XVI ${ }^{\mathrm{e}}$ siècle entraîne une recrudescence de tous ces bruits. La France ne reste pas insensible à ces cris, d'autant que, depuis la fin $\mathrm{XV}^{\mathrm{e}}$ siècle, elle affronte l'Espagne sur les différents champs de bataille européens.

Soupçonnés de vouloir créer un empire universel envers et contre tous, n'hésitant pas à recourir à l'assassinat politique pour parvenir à leurs fins, les Castillans font l'objet d'une vaste campagne de dénigrement en France tout au long du siècle. Ainsi, en 1536, certains pamphlétaires ont vu la main de Madrid derrière la mort du dauphin de France, le fils de François $1^{\mathrm{er}}{ }^{16} \mathrm{La}$ publication en 1552 de la Brevissima relacion de la destruccion de las Indias par Bartholomé de Las Casas et les événements de la guerre civile aux Pays-Bas fournissent aux pamphlétaires des guerres de religion de nombreux exemples de "l'atrocité" des soldats de Philippe II et du triste sort qui attend les Français s'ils laissent Madrid prendre possession de la France.

Dans ses pamphlets, Arnauld joue uniquement sur les peurs primaires de la population, face à ce qu'il présente comme une entreprise de conquête de la part de Madrid. ${ }^{17}$ Il décrit la triste vie des Espagnols sous la férule d'un roi tyrannique, qui ne respecte ni l'Église qu'il prétend pourtant défendre, ni ses sujets. Il dépeint dans les deux Philippiques à la France la condition atroce dans laquelle sont tombées les populations maintenant placées sous la domination espagnole, comme les Indiens d'Amérique ou les habitants des PaysBas. ${ }^{19}$ Rarement il s'en prend directement aux Français qui soutiennent le parti ligueur. Il ne s'attaque nommément qu'au président Jeannin qui, en 1592, est allé à Madrid offrir la couronne de France à une infante espagnole, ${ }^{19}$ au Duc de Mayenne, chef nominal du parti ligueur, qui préfêre la domination d'un Philippe II à celle d'Henri IV, et au marquis de Vitry qui, fidèle serviteur d'Henri III, est allé tout de suite après l'assassinat de ce dernier plier le genou devant ses meurtriers présumés. ${ }^{20}$

Se conformant aux principes avancés par le Béarnais, Arnauld cherche à pardonner aux Français leur engagement contre leur roi légitime. Séduits par l'or espagnol ou trompés par les discours des prédicateurs et des Jésuites, les ligueurs font davantage preuve d'irresponsabilité que de mauvaise volonté. On ne retrouve pas dans les pamphlets de notre avocat des attaques contre le 
système politique que certains de ses collègues croient déceler au sein du parti des catholiques extrémistes, soupçonnés de vouloir abattre la monarchie pour instaurer la démocratie. Il n'en fait mention que vaguement à une seule reprise. $^{21}$

Malgré son gallicanisme virulent, qui se manifeste surtout dans ses textes écrits contre les Jésuites, Arnauld ne s'attaque pas non plus à l'ingérence de la papauté dans les affaires temporelles françaises de cette époque. Cette ingérence n'est pourtant pas négligeable: en mai 1589, Sixte Quint excommunie et dépose Henri III. En septembre 1585, il avait déjà déclaré Henri de Navarre et Henri de Condé inaptes à monter sur le trône français, déclaration renouvelée par Grégoire XIV en 1591. Certains pamphlétaires critiqueront sévèrement ces interventions. ${ }^{22}$ Arnauld, toutefois, fídèle à son discours anti-espagnol, accuse Madrid de manipuler complètement les Saints Pères. Marionnettes entre les mains de Philippe II et, avant lui, de Charles Quint, les Papes, tout comme les ligueurs, ne peuvent être tenus complètement responsables de leurs actes.

Arnauld s'attaque, dès 1590, à l'intervention de Madrid dans les affaires françaises. Mais, il faut bien l'avouer, il n'ajoute rien de neuf au discours anti-espagnol. Il reprend les thèses servies par tous les ennemis de l'Espagne à cette époque: l'ambition et la tyrannie des monarques, l'inhumanité de l'inquisition, l'intransigeance de la population et son fanatisme religieux, la cruauté lors de la répression des révoltes. Tout ce qui concerne l'Espagne sert en fait de contre-exemple aux qualités du roi de France, de ses sujets et de son royaume.

Ces textes permettent ainsi de voir quelles qualités Arnauld recherche chez un roi. Ses sujets ne connaissent pas Henri IV lorsqu'il monte sur le trône le $1^{\mathrm{er}}$ août 1589. Éloigné de la Cour depuis 1576, son retour auprès d'Henri III ne date que du 30 avril précédent. Lors de son séjour à la Cour de 1572 à 1576, il se fait remarquer par ses talents de danseur, de chasseur et par ses aventures amoureuses, laissant l'impression d'un prince léger. Cette image, bien qu'elle ne rende pas hommage à l'intelligence du Béarnais, correspond en partie toutefois à la réalité. En avril 1584, alors que la mort imminente du duc d'Anjou fera d'Henri de Navarre l'héritier présomptif de la Couronne, les principaux conseillers du Béarnais le convient à mener enfin une vie digne de sa nouvelle situation. ${ }^{23}$

Éloigné du gouvernement central, occupé à guerroyer, le nouveau souverain n'a pu apprendre les rouages de l'administration du royaume en participant, par exemple, au Conseil du roi. Les panégyriques qui lui sont adressés au début de son règne insistent donc sur ses vertus guerrières alors que son 
prédécesseur fut louangé, au début du sien, tant pour ses actions militaires que pour ses interventions passées au cours des séances du Conseil. ${ }^{24}$ De nombreux partisans du Béarnais se sentent donc justifiés de glisser dans leurs écrits des indications plus ou moins précises sur ce qu'ils attendent d'Henri IV.

Se servant du contre-exemple de Philippe II, "demi-maure, demi juif, demi-sarrazin," Arnauld demande un vrai Français comme souverain, ce qui lui permet d'écarter les prétendants de la maison de Lorraine à la succession au trône. ${ }^{25}$ La clémence d'Henri IV contraste avec la cruauté des rois espagnols, sa franchise l'emporte sur leur fausseté. Le Béarnais aime ses sujets, ne désire que leur repos, alors que Philippe II "ne semble être en terre que comme un fléau pour la battre." Le roi castillan n'ose pas affronter lui-même les armées ennemies. Il se terre derrière ses montagnes et envoie sa noblesse se faire massacrer à sa place. Cela ne le dérange pas, car il craint les nobles, n'a pas confiance en eux. Jaloux de tout le monde, il interdit à ses sujets de se rencontrer de peur qu'ils ne complotent contre lui. Ceux-ci ont appris à s'opposer et à se révolter devant les impôts excessifs levés par Madrid. Le peuple ne doit attendre de Philippe II que le mépris, l'esclavage, la mort.

Henri IV, de son côté, aimera ses sujets, et particulièrement sa noblesse. Il écoutera ainsi les conseils de celle-ci pour l'aider à administrer convenablement le royaume. Loyaux, ses sujets pourront avoir confiance en lui. Généreux, mais non dépensier, il ne sombrera ni dans l'avarice, ni dans une trop grande libéralité. Il garantira un règne de paix aux Français, ce qui lui permettra de maintenir à un niveau acceptable les impôts. Roi clément, il évitera les punitions injustifiées et inutiles. Roi juste, il fera en sorte que la justice et ses mandataires soient respectés. Il s'assurera du redressement de la religion, veillant à ce que les abus disparaissent de l'Église et à ce que les huguenots rejoignent tranquillement le giron de celle-ci. Mais, avant toute chose, le roi cherchera à pacifier son royaume.

La politique de réconciliation nationale mise de l'avant par Henri IV vise à appaiser les tensions franco-françaises, non à les entretenir. Arnauld utilise les Espagnols comme un exutoire à ses passions. Il ne tente pas de cacher les "crimes" commis par les membres du parti catholique, mais plutôt de les expliquer. Il fait appel, dès lors, à des faiblesses bien humaines pour excuser leur révolte: stupidité, légèreté, cupidité, ambition. On le surprend même à prendre pitié de ces "pauvres ligueurs, à qui le jugement et la prévoyance ont toujours plus défailly que la bonne volonté." 26 Toutefois, Arnauld ne pardonne pas à certains membres du clergé d'avoir "converti en fiel la douceur 
de la parole divine." ${ }^{27}$ Les prédicateurs méritent le sort que leur réserve Henri IV: l'exil.

Chassés progressivement du royaume, les Espagnols ne représentent plus une menace véritable pour la sécurité nationale à la fin de l'année 1594. Toutefois, leurs agents, les soldats choisis par Philippe II pour "attiser et allumer continuellement ce grand feu, dans lequel cette monarchie a quasi été consumée". sont toujours présents en France et vivent impunément au coeur même de Paris, à deux pas du Louvre et du roi.

En bon gallican, Arnauld ne pouvait tolérer la présence des Jésuites en France. La "conjuration" Papauté-Espagne-Société de Jésus représente, à ses yeux, une menace directe pour les droits et privilèges de l'Église en France. Dans ses textes, il s'attarde peu sur les débats théologiques entourant la question des Jésuites: sont-ils réguliers ou séculiers? Que penser du nom même de l'ordre? Arnauld s'intéresse davantage aux actes perpétrés, ou supposément perpétrés, par des membres de la Compagnie lors des guerres civiles.

Le rôle joué par les Jésuites pendant les guerres de religion demeure assez confus. En 1585-86, alors qu'un des leurs, le père Edmond Auger est le confesseur attitré d'Henri III, ses collègues Claude Matthieu et Henri Samier travaillent activement pour le duc de Guise. Le provincial de l'ordre, Odon Pigenat, et le général Aquaviva tentent de garder une certaine neutralité, mais ne réussissent pas à la faire respecter par leurs ouailles. Il semble bien qu'il existe deux factions au sein de l'ordre à cette époque: une gallicane, plus proche du roi, et une autre ultramontaine, fidèle à la Ligue. ${ }^{28}$ Quelle fut alors l'attitude des Jésuites au cours des premières années du règne d'Henri IV? Certains font d'eux les moteurs de la Ligue, d'autres les modérateurs. ${ }^{29}$

Arnauld s'attaque vigoureusement à la Société de Jésus qu'il accuse de vouloir s'emparer, pour le compte du roi d'Espagne, des richesses et de l'âme des Français. Prêts à tout pour atteindre ces objectifs, les Jésuites s'en prennent aux bases mêmes de la nation, notamment aux liens unissant les sujets à leur roi. Deux propositions soutenues par quelques-uns d'entre eux soulèvent particulièrement l'ire d'Arnauld. La première concerne le pouvoir du pape de délier les sujets du serment d'allégeance au souverain. La deuxième affirme qu'un monarque excommunié par le pape peut être assassiné en qualité de tyran. Ces propositions viennent en parfaite contradiction avec les doctrines de l'Église gallicane, défendues passionnément par Arnauld. Dès lors, il accuse la Compagnie d'avoir armé Jacques Clément, le meurtrier d'Henri III, et d'avoir fomenté toutes les tentatives d'assassinat politique commises en Europe au cours de la deuxième moitié du XVI $\mathrm{XI}^{\mathrm{e}}$ siècle. 
L'acharnement d'Arnauld contre les Espagnols, puis, une fois que le danger représenté par ceux-ci s'estompe, contre les Jésuites, est avant tout politique. A la recherche d'outils en faveur de la réconciliation nationale, il tente de canaliser les énergies des Français contre des ennemis extérieurs à la nation. Ce faisant, Arnauld n'agit pas seul: de nombreux écrits anti-Jésuites restés jusque là à l'état de manuscrits sont publiés simultanément en 1595.

La hargne de notre avocat contre les Jésuites vient-elle du fait qu'il favorisait en secret le calvinisme? De nombreuses personnes ont voulu le faire croire. C'est le cas, entre autres, de Philippe Hurault de Cheverny, chancelier du royaume, qui prétend que les "calomnieuses allégations" d'Arnauld et de Louis Dolé, qui représentait au procès les curés de la capitale, "ne servirent à la fin que de les faire reconnaître pour tels que chacun les soupçonnait."30 Le jésuite Louis Richéome qui, en 1595, répond sous le couvert d'un pseudonyme au plaidoyer d'Arnauld affirme, dès l'avant-propos de sa défense, que les protestants se cachent derrière les attaques du parlement. ${ }^{31}$

Les huguenots devaient, en effet, espérer le renvoi hors de France d'un ordre religieux voué à l'éradication de l'hérésie et à l'éducation catholique de la jeunesse. Mais, bien qu'élevé au sein d'une famille protestante, Arnauld professe régulièrement dans ses textes son attachement au catholicisme. Celui-ci a joué, selon lui, un rôle important dans l'histoire nationale puisque "son commencement en France achève de trancher le lien de la servitude du Romain."32 Arnauld voit donc dans la religion catholique un symbole de l'indépendance du royaume. Sa haine des Jésuites vient davantage de son attachement au gallicanisme qu'à une hypothétique foi protestante.

On peut toutefois se surprendre du ton adopté par Arnauld dans son plaidoyer. De nombreux auteurs ont mis en lumière les exagérations, les erreurs, les invraisemblances que l'on retrouve dans cette furieuse diatribe. Le père Richéome affirme y avoir relevé "plus de trois cents mensonges évidents, et environ deux cents calomnies; d'ignorance, et sottises à force."33 Pourquoi, alors que Paris vient tout juste de se rendre au roi et que la France est sur la voie de la pacification, faire retentir encore une fois les trompettes de la guerre? Pourquoi le faire alors que, depuis son accession au trône en 1589, Henri IV appelle les Français à l'oubli des fautes passées?

Outre la théorie du "complot" protestant évoquée plus haut, certains historiens ont avancé que l'Université de Paris cherchait à faire oublier au plus vite le soutien qu'elle avait elle-même accordé à la Ligue en déclarant, entre autres, Henri de Navarre inapte à monter sur le trône de France. Charger les Jésuites de tous les maux servait ainsi à décharger la conscience de ceux qui pouvaient avoir quelques repròches à s'adresser quant à leur attitude lors 
des guerres civiles. ${ }^{34}$ Les Jésuites, présentés comme une troupe de soldats étrangers, remplacent les Espagnols comme exutoire aux passions françaises. De plus, il est indéniable que les parlementaires gallicans désiraient se débarasser d'ultramontains aussi ardents et que l'Université voulait régler une querelle vieille de plus de 30 ans. ${ }^{35}$ Mais s'il avait probablement ces idées en tête, Arnauld pense surtout à une chose: la survie du roi. Telle sera la hantise des parlementaires durant tout le règne d'Henri IV; telle est l'idée qui explique la virulence de la polémique anti-jésuite au tournant du XVII ${ }^{\mathrm{e}}$ siècle.

Les magistrats perçoivent Henri IV d'abord et avant tout comme un guerrier ne détenant pas la formation requise pour devenir un bon chef de gouvernement. La vivacité de son esprit, si utile lors d'une bataille, lui permet de prendre des décisions politiques rapides, mais ses conseillers doivent soigneusement lui préparer auparavant le terrain. ${ }^{36}$ Cette opposition entre le roi soldat et le roi gouvernant perturbe les parlementaires qui rappellent fréquemment à Henri IV qu'il ne règne pas pour lui seul, qu'il a la responsabilité de ses sujets, qu'il doit donc rester en vie en prenant moins de risques, particulièrement à la guerre. ${ }^{37} \mathrm{Si}$ les magistrats ne peuvent empêcher le Béarnais de charger à la tête de ses troupes, comme il le fait régulièrement, ils peuvent le prémunir contre les assassins éventuels que sont les Jésuites et leurs élèves.

Cette phobie du tyrannicide explique pourquoi le parlement de Paris, profitant d'une cause qui ne le concernait en rien, renouvelle son arrêt d'expulsion contre les Jésuites en $1597 .{ }^{38}$ Elle explique également la vigueur de la polémique anti-jésuite lors de leur rappel par Henri IV en 1603 et lors de l'assassinat du roi en 1610. Arnauld s'en fait l'écho: dans son plaidoyer de 1594 et dans le Franc et véritable discours de 1602, il supplie le roi de penser à sa survie.

La mort du roi replongerait la France dans le chaos des guerres civiles. Les théories avancées par des jésuites tels Juan de Mariana et Emmanuel Sa, théories soutenant le tyrannicide, inquiètent au plus haut point les parlementaires qui, après plus de 30 ans de guerres civiles, désirent voir la France vivre en paix et le roi s'attaquer aux problèmes de base qui ont favorisé le développement des troubles: une fiscalité trop élevée, une justice trop peu respectée, des privilèges accordés à tort et à travers, le mérite et la vertu supplantés par la richesse. Pour mettre un terme à ces excès, la stabilité du gouvernement est indispensable; le royaume a besoin d'un gouvernement central fort, d'un règne paisible, d'un règne d'une longue durée et d'une succession au trône assurée. 
Henri IV doit vivre. Tant du point de vue psychologique que sur le plan politique, la survie du roi prend une importance énorme. Depuis 1589 , le Béarnais est présenté comme l'"Hercule français," celui qui, par sa vaillance, mettrait un terme aux guerres civiles. Suite à 40 ans de règne assurés par des rois faibles, mineurs ou impuissants, la propagande royale fait de son champion le panacée à tous les maux de la France. Élu de Dieu, Henri IV est le roi providentiel, le sauveur du royaume. De là découlent la hantise des magistrats quant à la survie du roi et leur crainte des Jésuites. ${ }^{39}$

L'accent mis sur cette question montre le clivage existant parmi les parlementaires d'Henri IV. Les adversaires des Jésuites au sein du parlement mettent d'abord de l'avant la stabilité politique du royaume ou la défense d'institutions nationales telles que l'Université de Paris ou l'Église gallicane. Les défenseurs de l'ordre pensent, eux, à la sauvegarde de la religion catholique ou même à leurs intérêts personnels: pour certains d'entre eux, la gratuité de l'éducation dispensée par les Jésuites prend une grande importance. ${ }^{40} \mathrm{~L}$ 'indépendance nationale face à la primauté de la religion, et la survie à tout prix des institutions selon les anciennes coutumes opposée aux intérêts particuliers de leurs membres: les divisions du parlement d'Henri IV tourneront toujours autour de ces deux questions.

Les Jésuites ne furent pas les seuls ecclésiastiques à s'impliquer dans la Ligue, mais Arnauld ne s'intéresse pas aux ordres qui ne sont pas liés à la théorie du tyrannicide. Contrairement à ce que l'on serait peut-être en droit de s'attendre de la part d'un anti-ligueur acharné, il ne se livre pas non plus à une attaque en règle contre le rôle dominant joué par les gens d'Église dans la vie politique et sociale de la nation durant les guerres civiles. Ceux-ci ont pourtant été les hérauts de la rébellion, diffusant constamment dans leurs sermons les mots d'ordre des Seize, les chefs de la Ligue parisienne.

Arnauld ne revient pas sur ce sujet. Pourtant, au cours de cette période, de nombreuses personnes s'interrogent sur la place exacte que devaient occuper les ecclésiastiques au sein de la société. Arnauld se contente de signaler l'importance des prélats dans le maintien du catholicisme en France, notamment par la supervision du travail des prêtres et des curés de leurs diocèses. ${ }^{41}$ Il ne formule aucune remarque à l'endroit de ces derniers.

Ainsi, Arnauld n'aborde jamais les aspects canoniques du gallicanisme, c'est-à-dire l'organisation ecclésiastique même du royaume. Il se contente de proclamer l'indépendance du roi face à Rome ou face à toute domination étrangère. A ce titre, son gallicanisme se rapproche de celui de Pasquier, de de Thou ou de Leschassier et s'éloigne de celui d'anciens parlementaires ligueurs, tels Hotman ou Lasnier de l'Effretier qui, désireux de faire oublier 
leur passé ultramontain, défendent une conception plutôt modérée des libertés à accorder à l'Église gallicane. ${ }^{42}$

Malgré cet attachement sincère à son Église nationale, Arnauld est prêt à tolérer provisoirement la coexistence de deux religions au sein de la nation. Il reprend à son compte les idées sous-jacentes à tous les édits de tolérance signés par les rois de France de 1562 à 1598: la tolérance est perçue comme une mesure provisoire permettant, à moyen ou long terme, l'établissement de la concorde. ${ }^{43}$

Pouvait-il adopter une autre position? Le dilemme, tel que se le posent les Politiques à la fin des guerres de religion est, somme toute, assez simple: "il ne nous reste plus autre chose, ou que de nous ruiner et périr tous ensemble, sans que l'un ait à se moquer de son compagnon: ou, de laisser vivre les uns et les autres en paix et liberté de conscience." 44 L'idée de tolérance a ainsi fait beaucoup de chemin au cours des guerres civiles. Deux hommes reconnus pour leur modération au milieu du $\mathrm{XVI}^{\mathrm{e}}$ siècle, Estienne de La Boétie et Michel de Montaigne, soutenaient pour leur part que la tolérance équivalait à céder à la violence, à légitimer l'opposition à la volonté royale. ${ }^{45}$

En dépit de son gallicanisme farouche, Arnauld, à l'inverse de certains de ses contemporains, y compris quelques prélats, ne recherche pas le schisme avec Rome. ${ }^{46}$ Il ne croit pas non plus qu'un concile national puisse régler le différend religieux. Il préfère laisser le temps faire son oeuvre, convaincu que la patience et l'éducation ouvriront les yeux des protestants et les inciteront à rejoindre le giron de l'Église catholique, ou plutôt de l'Église gallicane.

Uni au sein de cette Église, les Français ne peuvent se permettre de laisser subsister d'autres tensions entre eux, particulièrement des tensions sociales. Or, l'animosité est grande entre nobles de robe et nobles d'épée à la fin du $\mathrm{XVI}^{\mathrm{e}}$ siècle. Les premiers essaient de s'extirper du Tiers-État, alors que les seconds s'y opposent car, selon eux, cela signifierait un nivellement social dans la roture.

De nombreux historiens tendent maintenant à minimiser les différences fondamentales que l'on percevait auparavant entre aristocrates et robins, à considérer ces deux groupes comme une seule classe ayant plus ou moins de cohésion. Ce fait est reconnu d'ailleurs par des magistrats vivant loin de la capitale. ${ }^{47}$ Toutefois, si ce schéma s'applique aux provinces, au sein de parlements créés récemment, on ne le retrouve pas à l'intérieur du parlement de Paris où la tradition d'indépendance des parlementaires face au pouvoir central et à la noblesse est plus ancrée. Il ne s'agit pas de dire que les relations entre robins et nobles d'épée sont inexistantes à l'intérieur de la capitale, bien au contraire. De nombreux magistrats oeuvrent au sein des maisons des 
grands du royaume. Les contacts entre ces deux groupes sont quotidiens. Toutefois, sur le plan politique, les frictions demeurent. Gravitant quotidiennement autour du pouvoir central et se posant tous comme les conseillers privilégiés du roi, robins et aristocrates ne peuvent que s'affronter sur la question de leur place respective dans l'administration du royaume.

La faiblesse ou l'impuissance des rois qui règnent de 1559 à 1589 incite les différents groupes politiques ou sociaux à tenter d'accroître leur influence au sein du royaume et de l'appareil gouvernemental. Ces divisions sont encore bien présentes à la fin des guerres civiles et se manifesteront, par exemple, lors de l'assemblée des notables tenue à Rouen en $1596 .{ }^{48}$ Henri IV et ses alliés doivent s'y faire face. Fier d'être un robin, Antoine Arnauld ne montre pourtant aucune rancoeur à l'égard de l'ancienne aristocratie dont il respecte l'utilité publique et didactique.

Un sentiment anti-nobiliaire se développe tout au long des guerres de religion. Chargés (officiellement) de protéger le roi et de défendre la population contre les invasions étrangères, les nobles d'épée pillent villes et campagnes tout en essayant de s'assurer le contrôle des principautés indépendantes au détriment du pouvoir central. L'animosité à leur égard affecte nécessairement les robins, qui désirent former avec l'ancienne noblesse un seul tout. Or, qui serait intéressé à s'unir à un groupe déprécié par l'ensemble de la population? Deux choix s'offrent alors à eux: soutenir qu'une nouvelle noblesse, celle de robe, doit supplanter l'ancienne aristocratie ou, compte tenu de l'importance des vertus guerrières dans l'idéologie populaire, s'efforcer de redorer le blason de la noblesse d'épée pour pouvoir jouir, une fois l'union des deux noblesses accomplie, des lauriers des anciens nobles. Arnauld adopte cette dernière position.

L'utilité publique des nobles d'épée ne fait aucun doute à ses yeux. Ceux-ci doivent défendre le royaume contre ses ennemis extérieurs. L'histoire de France, citée à maintes reprises par Arnauld, se voit remplie des hauts faits du premier ordre de la nation "qui au prix de son sang acquiert à son Roy la gloire et l'honneur des batailles." 49 Par ailleurs, la noblesse des parlementaires "se voit encore plus illustre, pour être sortie des parlements." 50 Les deux groupes jouissent des mêmes qualités les différenciant du populaire: vertu, mérite, courage, valeur des ancêtres, environnement familial favorable. Se sentant membres à part entière de cette aristocratie attaquée par une large part de la population, Arnauld se croit obligé de la défendre. Il la place alors sous la protection du roi, arguant que, si sans roi la noblesse n'est rien, sans noblesse le roi n'existerait pas. 
Il semble donc qu'Arnauld ait appuyé toutes les facettes de la politique royale de réconciliation nationale: réconciliation politique, réconciliation religieuse, réconciliation sociale. Son appui va plus loin. Ainsi, bien que généralement peu préoccupé par les questions économiques, il soutient tout de même les idées mercantilistes avancées par Henri IV, Sully et certains de leurs collaborateurs, tels Olivier de Serres ou Barthélémy de Laffemas, en vue de favoriser l'économie nationale: développement industriel, balance commerciale positive, développement de la marine, développement de colonies comme la Nouvelle-France. ${ }^{51}$ Mais l'idylle ne dure pas. Tout en gardant tout son respect pour le roi, Arnauld ne fera bientôt plus confiance au gouvernement.

Après 30 ans de guerres civiles, la France ressent le besoin se se stabiliser. Les Français recherchent non seulement une sécurité théologique, comme le montre le renouveau catholique au début du XVII ${ }^{\mathrm{e}}$ siècle, mais également une sécurité plus positive à tendance politique. ${ }^{52}$ La majorité d'entre eux désirent un roi fort, capable de maintenir la paix à l'intérieur du royaume. Les penseurs proches du mouvement des Politiques accorderont, dans leurs ouvrages, de plus en plus de pouvoirs au souverain, favorisant le développement de l'absolutisme. Cette évolution plaît d'ailleurs à Henri IV qui, s'il accepte et recherche même les conseils, tient à ce que les décisions finales lui reviennent et que sa volonté soit suivie par tous.

La défense des privilèges corporatifs, religieux ou politiques s'accorde mal avec l'obéissance au gouvernement et à son premier représentant, le roi. Mais, seul ce dernier est capable de stabiliser le royaume. Henri de Navarre, désigné par la loi salique pour régner, doit prendre en main les destinées de la nation. Il le fait en tentant de centraliser les pouvoirs, ce qui ne peut manquer de provoquer certaines tensions. ${ }^{53}$

En fait, des conflits éclatent, car, alors qu'il tente de reconquérir son royaume, Henri IV ne laisse pas supposer qu'il va adopter plus tard un mode de gouvernement de type absolutiste. Occupé à rallier des individus à sa cause, il donne aux élites nationales l'impression d'être un roi conciliant, voire faible. Les Politiques qui, eux, désirent un monarque fort, s'inquiètent d'ailleurs de la complaisance du roi face à ses anciens ennemis. Les nécessités inhérentes à la reconstruction du royaume à la fin des guerres de religion amènent finalement le Béarnais à dévoiler son vrai visage. Les partenaires du pouvoir royal réagiront à ce changement d'attitude. 
Ainsi, certains juristes de province, au service des grands du royaume, se battent pour conserver à leurs maîtres leurs anciens privilèges. Guy Coquille, procureur général du duc de Nevers, est peut-être le plus connu d'entre eux. ${ }^{54}$ Des villes tentent également de préserver leurs anciennes libertés. ${ }^{55}$ Les parlemetaires parisiens, pour leur part, s'inquiètent de cette situation. Henri IV, mal conseillé, prend des décisions contraires aux intérêts de la France. Loin de régler les problèmes ayant entraîné le royaume dans le tourbillon des guerres de religion, il les amplifie. ${ }^{56}$

Pressé par les nécessités de la guerre contre l'arrière garde ligueuse, l'Espagne ou la Savoie, le roi multiplie les édits financiers extraordinaires. Le parlement refuse de les enregistrer, arguant que le peuple en souffrirait trop. Si Henri IV veut trouver de l'argent, qu'il assainisse l'administration de ses finances, lui répondent-ils. S'il veut être respecté, qu'il fasse en sorte que sa Justice et ses officiers soient respectés à la grandeur du royaume. Le souverain demandé par les parlementaires pendant les guerres de la Ligue, celui-là que voudrait voir régner Antoine Arnauld, ne correspond pas au "nouvel" Henri IV.

Aux yeux des parlementaires, le Béarnais n'est pas entièrement responsable de ce qui arrive. Il se laisse manipuler par ses conseillers, plusieurs d'entre eux étant d'anciens ligueurs. Le roi devrait s'en débarasser et créer, avec l'aide du parlement, un nouveau conseil composé de nobles d'épée, de robins, de financiers soucieux de l'état du royaume et du bonheur des sujets. ${ }^{57}$ Mais le roi refuse. Le parlement ne dispose donc plus que d'une arme pour tenter de guider Henri IV “dans la bonne direction:" il s'agit de bloquer l'enregistrement des édits royaux et de faire des remontrances au roi afin de lui présenter des alternatives à sa démarche.

Le parlement vérifie les édits et ordonnances du souverain pour s'assurer qu'ils soient conformes à la loi et à la justice, qu'ils soient "justes et raisonnables." L'imprécision de ces termes, le manque de clarté du processus de vérification permettent tous les abus: "le pouvoir et l'attribution du Parlement se connaissent mieux par l'usage que par l'institution," affirme un traité datant du règne de Louis XIII. ${ }^{58}$ Les magistrats en profitent pour bloquer régulièrement les initiatives royales et dénoncer les mauvais conseillers du roi.

Le principe du gouvernement par conseil est né en France en même temps que la monarchie. Les individus les plus importants du royaume composent les premiers conseils du roi, appelés parlements. La multiplication des affaires force Philippe le Bel à sédentariser la cour. Alors que le parlement continue à s'occuper des affaires civiles et criminelles, le Grand Conseil, qui 
accompagne le monarque dans ses déplacements, s'intéresse sur une base quotidienne aux affaires de l'État. Les circonstances amènent toutefois au fil des ans les rois de France à requérir l'appui juridique des magistrats dans le cas des affaires politiques. Graduellement, le pouvoir d'enregistrement des Cours souveraines s'étend à ce domaine, pour devenir incontournable sous Henri IV.

Les ordres du monarque étant, selon Arnauld, sans appel, la ou les limites de son pouvoir doivent être placées à l'intérieur du processus de décision. Malgré la place qu'ils lui accordent au dessus de la loi, les penseurs politiques de l'époque considèrent que le roi peut errer en celle-ci et être corrigé par ses cours souveraines. C'est le frein de justice présenté par Claude de Seyssel au début du XVI e siècle, que tous les auteurs reprendront à leur compte. ${ }^{59}$ Arnauld, pour sa part, insiste moins sur le pouvoir pratique de vérification des parlements - il ne s'interroge jamais sur les questions qui sont du ressort du parlement - que sur l'importance théorique de répondre aux besoins et attentes des sujets.

Si les ordres du souverain doivent être respectés, ce dernier se doit toutefois de prendre le pouls de la population avant de les dicter. ${ }^{60}$ L'enjeu pour les différents "groupes de pression" du début du XVII e siècle sera d'avoir l'oreille du roi, de se faire valoir comme les plus aptes à le conseiller. Arnauld en est bien conscient: "Les Rois ne voient que par les yeux d'autrui, n'entendent que par les oreilles étrangères," affirme-t-il. ${ }^{61}$

Mais la meilleure façon de connaître l'avis des sujets ne consiste-t-elle pas à convoquer les États-Généraux de la nation? Ceux qui se sont tenus pendant les guerres de religion laissent un souvenir amer aux Français. Les derniers en date, assemblés par la Ligue en 1593, ne devaient-ils pas procéder à l'élection d'un roi en dépit de la loi salique? Bien que certains théoriciens appuient encore fermement cette institution, Henri IV ne veut pas y faire appel. ${ }^{62}$ Il préférera convoquer en 1596 une assemblée des notables, institution para-légale, pour discuter des problèmes qui assaillent la France à cette époque.

Quoiqu'il accorde beaucoup d'importance au peuple (compte tenu de la définition qu'il donne au mot "peuple," cf. n. 60) et qu'il reconnaisse la valeur des États-Généraux qui "connaissent nieux que tous les autres, l'humeur de leur nation," ${ }^{63}$ Arnauld, jaloux des privilèges du parlement, n'est pas prêt à accorder à la population ou à une autre institution un rôle direct dans la conduite des affaires de la nation. Seul le parlement peut conseiller adéquatement le roi sur une base quotidienne, puisque les États-Généraux ne se réunissent qu'occasionnellement. 
Arnauld, contrairement à son beau-père Simon Marion, ne fait pas du parlement un abrégé des États-Généraux. ${ }^{64}$ La cour, ou le peuple, ne peut donc jamais imposer sa volonté au roi. Homme passionné, jaloux des privilèges parlementaires, Arnauld s'efface devant la "raison d'État" et la volonté royale. Il pardonne aux ligueurs leur insurrection contre le roi légitime car tel le veut celui-ci. Malgré ses virulentes sorties à leur endroit, il ne s'attaque plus publiquement aux Jésuites après leur rétablissement par Henri IV. En cela, il met en pratique ce qu'il prêche lui-même: les désirs du souverain se doivent d'être suivis par tous, à la grandeur du royaume. ${ }^{68}$

Cela ne signifie pas qu'il accepte aveuglément la politique d'Henri IV et de certains de ses ministres qui veulent confiner les cours souveraines à un rôle purement juridique. Ceux-ci confient de plus en plus de tâches et de pouvoirs à des commissaires et à des intendants au détriment des parlements. Également, le roi élargit la pratique de la vénalité des offices, malgré l'opposition à laquelle il fait face de la part des nobles, des ecclésiastiques et d'une partie des officiers. Les parlementaires doivent aussi contrer les ambitions des nobles d'épée. Ces derniers, dans leur ensemble, jugeaient absolument nécessaire la présence des princes du sang, des grands officiers de la Couronne et des pairs au Conseil du roi. Certains d'entre eux soutenaient de plus que seuls les gentilhommes avaient le droit d'y siéger. ${ }^{66}$ De telles visées ne pouvaient qu'aiguillonner les prétentions des robins.

Arnauld, nous l'avons vu, ne doute pas de la valeur de la noblesse traditionnelle. Toutefois, il soutient que la conduite des affaires publiques doit revenir au monarque et aux cours souveraines, les nobles d'épée devant consacrer leurs énergies à défendre le royaume. Les affaires d'État demandent un minimum de stabilité politique aussi bien que territoriale. Occupés à courir les frontières nationales pour y repousser l'étranger, les aristocrates ne peuvent conseiller rapidement et efficacement le souverain puisqu'ils n'ont qu'une vision partielle du royaume et qu'ils se retrouvent bien souvent éloignés de lui. La stabilité politique des parlements au fil des ans et leur représentativité nationale leur assurent naturellement le rôle de principaux conseillers du monarque.

A l'instar de tous les historiens de son époque, Arnauld fait commencer l'histoire du parlementarisme en France au VIII ${ }^{e}$ siècle. Les plus grands monarques ont écrit cette histoire: Charles Martel en jeta les fondements; Pépin le Bref en autorisa l'établissement; Charlemagne, Hugues Capet et Philippe le Bel les renforcèrent. Arnauld s'attarde longuement à rapporter les exploits passés des parlements, n'hésitant pas à avancer l'idée qu'ils ont sauvé la France à maintes reprises du désastre. 
Partisan des cours souveraines, Arnauld attribue à celles-ci plusieurs actes que d'autres auteurs allouent aux États-Généraux. Cette confusion provient de l'origine commune, selon certains, de ces deux institutions. Ainsi, selon Loys Le Roy, le monarque avait coutume d'entendre les conseils de ses sujets lors d'assemblées périodiques. Devant séparer les plaintes personnelles de celles touchant au général de l'État, le roi donna mandat au parlement de s'occuper des premières alors qu'il continuait à convoquer annuellement les États-Généraux pour s'occuper des deuxièmes. ${ }^{67}$ Le Roy, contrairement à Arnauld qui se fie surtout aux Recherches d'Étienne Pasquier pour présenter son histoire du parlement, croit que ce sont les États qui contribuèrent à tirer le royaume de maintes situations difficiles.

Pour tous les penseurs politiques de l'époque, cependant, les personnages les plus influents du royaume se rassemblaient au sein des premiers parlements. Les nouveaux parlementaires se recrutant, depuis le début du XVI ${ }^{e}$ siècle, presque exclusivement dans le monde du barreau, la cour ne peut plus d'une façon ou d'une autre prétendre représenter l'opinion des grands corps socio-politiques de l'État. Pour pallier à ce problème, Arnauld insiste alors sur la répartition géographique des huit parlements de France. Se retrouvant aux quatre coins du royaume, ils sont à même de recueillir l'avis de l'ensemble des habitants du pays. Ils représentent alors "la forme universelle résultant des formes particulières des humeurs de chacun," ils servent de lien entre la population et le roi. ${ }^{68}$

Ce lien est indispensable. Il garantit le peuple contre toute tyrannie royale. Si l'ensemble des penseurs politiques de l'époque - et Arnauld en fait partie - concèdent des pouvoirs absolus au monarque, ils insistent pour rappeler que celui-ci a toujours soumis volontairement ces édits à la vérification des parlements. Le peuple, voyant que l'édit respecte la justice et le droit, l'accepte alors sans rechigner. ${ }^{69}$ Cela ne veut toutefois pas dire que la population possède un certain pouvoir sur le souverain.

Arnauld n'adhère à aucun moment à la théorie d'une monarchie "populaire." Celle-ci, mise de l'avant en 1573 par le protestant François Hotman, soutient que le peuple, à l'origine détenteur du pouvoir, a, pour des raisons d'ordre pratique, nommé un roi pour veiller à la bonne marche des affaires publiques, la population detenant toujours un droit de regard sur les décisions du souverain. Cette doctrine, reprise par les ligueurs à la mort de François, duc d'Anjou - mort qui faisait du huguenot Henri de Navarre l'héritier légitime du trône -, connut diverses fortunes à cette époque. ${ }^{70}$ Mais jamais Arnauld n'y souscrit, le respect de la loi salique étant trop important à ses yeux. 
L'autorité du monarque dépend en grande partie de sa légitimité. La monarchie française s'est construite grâce au travail continu des souverains qui se sont succédé sur le trône. Arnauld cite toujours en exemple de grands monarques tels que Charlemagne, saint Louis, Philippe le Bel, Louis XII. Pour ces rois, l'obéissance de leurs sujets se trouve à la base de la grandeur du royaume. ${ }^{71}$

Le roi peut-il alors se passer de l'avis des parlementaires? S'il ne formule pas de menaces précises à ce sujet, Arnauld donne de nombreux exemples de rois ou d'empereurs qui ont perdu leur trône pour ne pas avoir respecté les conseils de leurs cours souveraines. Ne s'attardant pas uniquement à des exemples tirés de l'Antiquité (Périclès, César ou Cléomène), Arnauld insiste sur le cas de Charles le Chauve "qui ravala beaucoup de son autorité par le mépris de ses parlements, autorité que depuis Louis le Bègue ne put mieux remettre, qu' en gagnant le coeur de ses sujets, les rétablissant en leur première gloire." 72 La force du gouvernement dépend de toute une série de facteurs, réels ou symboliques. Or, seuls le roi et les parlements peuvent se prévaloir d'une certaine puissance symbolique.

Tout comme ceux du souverain, les actes du parlement reflètent la volonté divine. La Justice est "l'instrument très parfait de la divinité; son bras le plus fort, son oeil le plus voyant, son âme, si je l'ose dire, ou du moins son plus naturel mouvement." Si la monarchie posséde un caractère religieux certain, il en va de même des cours de justice. De façon immédiate, le pouvoir des officiers vient du monarque; à l'origine, toutefois, leur puissance vient de Dieu. $^{73}$

Arnauld n'hésite pas à sacraliser la Justice et ses mandataires, les parlements. Il soutient que ceux-ci peuvent ceindre la Couronne de France, qu'ils peuvent se vêtir du manteau d'hermine des souverains, que les fleurs de lys ornent leurs trônes. Il fait ainsi appel aux éléments les plus visibles de la symbolique française pour démontrer l'importance des cours souveraines: le lys de la Vierge, devenus lys royaux, sacralisèrent la monarchie.

Est-ce à dire que les parlements ont un pouvoir indépendant du roi? Malgré ce qu'a pu en penser Pierre de l'Étoile, ${ }^{74}$ aucun magistrat ou penseur politique n'a jamais prétendu une telle chose. La justice est royale; les parlementaires la reçoivent en commission. Lorsque le roi siège au parlement lors de son Lit de Justice, les parlementaires s'inclinent devant son autorité. Toutefois, pour bien accomplir leurs tâches, les magistrats ont besoin d'un minimum d'autonomie.

En fait, Arnauld, tout comme bon nombre de parlementaires à cette époque, compare les parlements de France au sénat romain. Celui-ci avait pour 
mission de conseiller l'empereur sans le commander. Ce rôle est cependant primordial pour le royaume: "il n'y a chose qui ait plus ruiné de Républiques, que dépouiller le Sénat et les magistrats, de leur puissance ordinaire et légitime, pour attribuer tout à ceux qui ont la souveraineté."75 Tout ce que désirent les parlements, au début du XVII ${ }^{\mathrm{e}}$ siècle, c'est de voir le roi prendre leur avis en considération.

Pour accomplir adéquatement cette tâche qu'ils se donnent, les parlementaires doivent jouir d'une liberté relative. Pour que l'action de la Justice soit uniforme et respectée, il faut garantir la permanence de l'institution et de ses représentants. Arnauld demande au roi de manifester sa confiance envers le parlement et envers ses membres, en leur confiant davantage de responsabilités, en abolissant la vénalité des offices et restreignant l'utilisation des commissaires.

La vénalité des offices symbolise la division que l'on retrouve dans la milieu judiciaire à cette époque. Une partie des magistrats approuve cette pratique et appuie la Paulette, taxe annuelle instituée en 1604 qui assure au propriétaire d'une charge publique l'entière propriété de son office, car elle garantit leur mise de fond dans l'office. Toutefois, les parlementaires attachés aux traditions de leur institution s'insurgent de voir l'argent remplacer le mérite, l'or remplacer la vertu. ${ }^{76}$

Malgré tout, Henri IV continue dans la voie qu'il a choisie. La vénalité des offices, les abus des partisans - personnes qui achètent du roi un ensemble d'offices pour les revendre à leur profit -, l'utilisation des commissaires et des intendants empêchent Arnauld de faire confiance au gouvernement. En fait, il prédit la perte du royaume à plus ou moins longue échéance. En effet, selon lui, tout l'appareil gouvernemental perd de sa crédibilité auprès de la population en raison des malversations publiques commises par tous ceux qui n'ont à coeur que de s'enrichir. Les ponctions opérées dans le trésor public et dans les biens des familles par ces "éponges" provoqueront soit la révolte du peuple, et donc un écroulement de la nation par l'intérieur, soit la ruine des armées, et donc l'éffondrement de la France par l'extérieur. ${ }^{77}$

Malgré cette vision très pessimiste de l'avenir du royaume, Arnauld, tout comme l'ensemble des parlementaires, n'intrigue pas contre le roi. Une monarchie forte est nécessaire, surtout après 30 ans de guerres civiles. Les magistrats qui se soucient de la France s'opposeront souvent à Henri IV et à son gouvernement, non pour défendre des intérêts corporatistes comme on l'affirme généralement, mais parce qu'ils veulent que le roi s'attaque aux problèmes de base du royaume. "C'est en cette Compagnie où se redressent les fautes du gouvernement, et d'où sortent les résolutions qui maintes fois 
ont sauvé le royaume," affirme le conseiller Jean de Thumery dans une lettre à J. A. de Thou. ${ }^{78}$ La fidélité au souverain doit être inébranlable, mais le parlement doit s'assurer que le monarque reçoit de bons conseils et prend des décisions éclairées. Malgré ce qu'a pu prétendre récemment un historien français, leur attitude n'est en rien anti-monarchique. ${ }^{79}$

L'enregistrement de l'Édit de Nantes en février 1599 marque la fin de la dernière grande bataille entre Henri IV et le parlement de Paris. Certes, des conflits éclateront encore, mais sans atteindre des niveaux d'émotion comparables à ceux de 1595 ou $1597 .{ }^{80}$ Est-ce dire qu'Henri IV a gagné son pari de faire de la France un royaume unifié, pacifique? Son assassinat, le 16 mai 1610 , et les événements qui suivent sa mort, nous fournissent une réponse négative à cette question. Profitant des faiblesses inhérentes à tout gouvernement de régence - Louis XIII n'avait que neuf ans à la mort de son père -, les forces vives de la nation ressortent leurs anciennes protestations.

Marie de Médicis pense arriver à les mater en convoquant des États-Généraux en 1614. Elle réussit à en contrôler les élections. Mais, une fois réunis, les États auront une vie bien à eux, les trois groupes qui les composent y allant de leurs revendications traditionnelles. Ces revendications vont bien souvent à l'encontre des politiques d'Henri IV. ${ }^{81}$

* * * *

A plus d'un titre, Arnauld représente le juriste parisien typique du tournant du XVII ${ }^{\mathrm{e}}$ siècle. Dans une institution où, en 1600 , la plus grande partie des conseillers sont les premiers de leur famille à siéger, il s'intègre à la lignée traditionnaliste, bien qu'il ne soit pas membre à proprement parler du parlement. Il rejette les prétentions royales visant à confiner le parlement à un rôle juridique. Contrairement à beaucoup de ses confrères, il ne participera pas à la nouvelle administration centralisée. Certes, tout comme une majorité de ses collègues, il favorise ce type de gouvernement. Toutefois, il n'est pas prêt à sacrifier les pouvoirs du parlement pour pousser ce système jusqu'à sa limite ultime: l'absolutisme.

Tout au long de sa vie publique, Antoine Arnauld se montre dévoué à son pays et à son roi. Sa fidélité remonte aux premières étapes de sa carrière alors que, habitant d'une ville dominée par les ligueurs extrémistes, il n'hésite pas à prendre position pour le protestant Henri IV. Bien qu'il lui en coûte sûrement à quelques reprises, Arnauld plie toujours devant la volonté royale.

La légende qui entoure Henri IV permet de s'imaginer un souverain près de son peuple, aimé de tous. Pourtant, il ne réussit pas à obtenir immédiatement la confiance d' un groupe important de collaborateurs: les parlementaires 
traditionnalistes. Ceux-ci se fient à la force des coutumes pour dire le droit et encadrer un roi novice, qu'ils ne connaissaient pas lors de son arrivée sur le trône en 1589. La découverte de ce monarque, l'apprentissage du gouvernement à ses côtés, ne seront pas toujours faciles. La patience du Béarnais aura-t-elle raison de la pesanteur et de l'éloquence des parlementaires parisiens? Le Franc et véritable discours et La Justice aux pieds du roi témoignent de sursauts périodiques d'indignation de la part des magistrats. Leurs lettres montrent clairement que le Béarnais n'arrive pas à se faire respecter de nombre de ses sujets. ${ }^{82}$

Les parlementaires ne se rebellent pas contre leurs souverains. Cela va à l'encontre de tous leurs principes. Ils se contentent donc d'écrire des pamphlets et de bloquer encore l'enregistrement de certains édits. Leur opposition fait moins de bruit qu'au cours des premières années du règne. Le roi a réussi malgré tout à calmer les tensions françaises. Le royaume reprend vie peu à peu. Satisfait de la relative stabilité économique qui s'installe, le peuple ne tient pas à revivre les guerres civiles. Des révoltes populaires ou nobiliaires éclatent sporadiquement, mais elles ne mobilisent pas, ou plus, les passions nationales.

\section{Université McGill}

\section{Notes}

1. H. Fouqueray. Histoire de la Compagnie de Jésus en France des origines à la suppression, t. II (Paris, 1972), p. 360.

2. Il n'existe aucun ouvrage portant spécifiquement sur Arnauld. Voir R. Arnauld d'Andilly. Mémoires in A. Petitot. Collection des mémoires relatifs à l'histoire de France $2^{\mathrm{e}}$ série, t. 33 (Paris, 1819-1826), pp. 308-320; T. Froment. Essai sur l'histoire de l'éloquence judiciaire en France avant le dix-septieme siècle (Paris, 1874), pp. 147218; J. Pannier. L'Église réformée de Paris sous Louis XIII (Strasbourg, 1922), pp. 246-249; G. Tallement des Réaux. Historiettes, t. 1 (Paris, 1960-1961), pp. 504-514.

3. "Le vrai titre de gloire d'Arnauld, c'est moins encore le souvenir de ses discours que sa noble et forte postérité." Froment, Op. cit., p. 217.

4. Coppie de l'Anti-Espagnol fait à Paris (s. I., 1590); La première philippique à la France suivie de La deuxième philippique à la France (s. 1., 1592); La fleur de lys (s. 1., 1593).

5. Sur le sentiment national en France à cette époque, voir M. Yardeni. La conscience nationale en France pendant les guerres de religion (1559-1598) (Louvain, 1971).

6. Plaidoyé de M. Antoine Arnauld avocat en parlement, et ci devant conseiller et procureur général de la défunte Reine mère des Rois, pour l'Université de Paris demanderesse. Contre les Jésuites défendeurs. (Paris, Mamert Patisson, 1594). 
7. "Que si à son plaidoyer il eut apporté plus de modération et moins de passion, laquelle ordinairement est sujete au contrôle et à l'envie, il eut été trouvé meilleur de ceux même qui n'aiment pas les Jésuites, et qui les souhaitent tous aux Indes, à convertir les infidèles." P. de L'Estoile. Mémoires-journaux, t. 6 (Paris, 1879), p. 217.

8. Libre discours sur la délivrance de la Bretagne (s.1., 1598); La première Savoisienne (Grenoble, 1630).

9. Le franc et véritable discours au Roi. Sur le rétablissement qui lui est demandé pour les Jésuites (s. 1., 1602).

10. La justice aux pieds du Roi pour les parlements de France (s. 1., 1608).

11. Utile et salutaire avis au Roi pour bien régner (s. 1., 1614).

12. "Lettre de J. Gillot au Président J. A. de Thou" (B.N., Dupuy 675, fo 136-137): Cette lettre relate le tumulte que suscite au parlement la création de nouveaux offices en 1597 et expose le mépris ressenti par Gillot, un conseiller traditionnaliste, face à ses confrères "carriéristes."

13. G. Du Vair. De la constance et consolation es calamités publiques in Les oeuvres de Messire Guillaume Du Vair (Paris, 1641), pp. 369-370. Ce point sera reconnu par Henri IV comme on le voit dans Les lettres patentes du roi, pour le rétablissement de la Cour de parlement de Paris (Paris, 1594). Toutefois, certains parlementaires restés à Paris durant cette période, tel Louis Dorléans, donne un appui sans équivoque à la Ligue.

14. A. Loisel. Pasquier, ou dialogue des avocats du parlement de Paris (Paris, 1844), p. 104; B. La Roche Flavin. Treize livres des parlements de France (Bordeaux, 1617), p. 2.

15. Sur la légende noire espagnole, voir J. Juderias. La leyenda negra (Madrid, 1960); G. Parker. Philip II (Boston, 1978), pp. 200-212.

16. Copie de l'arrêt du Grand Conseil donnée à l'encontre du misérable et méchant empoisonneur de Monseigneur le Dauphin. Avec aucuns épîtres et rondeaux sur la mort de mon dit seigneur. (s. 1., 1536).

17. Coppie de l'Anti-Espagnol fait à Paris, p. 4.

18. Pour un discours similaire, voir Le masque de la Ligue et de l'Espagnol découvert (Tous, 1590), p. 48-63.

19. La seconde philippique à la France, pp. 36-41.

20. La fleur de lys (s. 1., 1593), pp. 46-47. Ses attaques contre Mayenne sont moins virulentes que celles que l'on peut trouver dans d'autres pamphlets de l'époque, tel L'Anti Charles Lorrain (s. 1., 1593), qui présente Mayenne comme un "exécrable tyran."

21. "Ils s'imaginent je ne sais quoi de tel qu'on voit ès Pays-Bas, où les États ont toujours fait quelque contrepoids à l'autorité plus absolue de leur souverain." Première philippique à la France, pp. 55-56. Pour une critique du "programme politique" ligueur, voir Lettre d'un gentilhomme Français, à Dame Jacquette Clément, Princesse boiteuse de la Ligue (s. 1., 1590); M. Hurault. Discours sur l'état de la France (Chartres, 1591), pp. 30-34. 
22. Voir, par exemple, deux textes de François De Clary: Les lauriers du roi, contre les foudres pratiqués par l'Espagnol (Tours, 1590), et Philippiques contre les bulles, et autres pratiques de la faction d'Espagne (Tous, 1592).

23. "C'est pourquoi vous avez à composer votre vie et vos actions, en sorte que, s'il est possible, il ne s'y trouve rien à reprendre; ains que chacun y puisse remarquer ce qui peut plus contenter son affection. [. . . Ces amours si découverts, et auxquels vous donnez tant de temps, ne semblent plus de saison. Il est temps, sire, que vous fassiez l'amour, et à toute la chrétienté, et particulièrement à la France." Lettre à $M M$. Duplessis, de Clervant et de Chassincourt, au roi de Navarre in Mémoires et correspondance de Duplessis-Mornay, t. II (Paris, 1824-1825), pp. 576-578.

24. A. Fumée. Panégyrique pour la bienvenue et retour du Très-Chrétien Henri, Roi de France et de Pologne (Paris, 1574). Henri IV, roi contesté, fait appel à la propagande pour affermir sa prétention à régner. Ses panégyristes sont donc beaucoup plus nombreux. Citons, entre autres: le Panegyric au Très-Chrétien Henri IIII, roi de France et de Navarre, par S.D.I.E.S.L.(Tours, 1590); Le panégyrique adressé au roi de la part de ses bons sujets de la ville de Paris (s. l., 1590); G. Joly. Panégyrique au roi Henri IIII (Paris, 1594).

25. Cette discussion repose sur de nombreux passages des quatre pamphlets écrits par Arnauld pendant les guerres de religion, Il serait beaucoup trop fastidieux de citer pour chaque trait de caractère dépeint l'extrait du texte s'y rapportant.

26. La seconde philippique à la France, p. 4.

27. La première philippique à la France, p. 73.

28. A. L. Martin. Henry III and the Jesuit Politicians (Genève, 1973).

29. Pour une illustration de ce débat, voir F. Desjardin. Les Jésuites et l'Université devant le parlement de Paris au XVI siècle (Paris, 1877) qui s'en prend à la Société; et la réponse de É. de Pontal. L'Université et les Jésuites. Deux procès en cour de parlement au XVI ${ }^{e}$ siècle (Paris, 1877) qui les défend.

30. Mémoires de Cheverny in Petitot. Op. cit., $1^{\text {ère }}$ série, t. 36, p. 285.

31. F. des Montaignes. La vérité défendue pour la religion catholique (Francfort, Wilhem der Sclaffer, 1595). Ces allégations, que Richéome reprendra régulièrement par la suite, trouvent écho chez bon nombre d'auteurs favorables aux Jésuites.

32. Coppie de l'Anti-Espagnol fait à Paris, p. 5.

33. F. des Montaignes. Op. cit., p. 22.

34. S. Linguet. Histoire impartiale des JésuitesD, t. II (s. l., 1768), p. 399; A. Douarche. L'Université de Paris et les Jésuites (XVIe et XVII e siècles) (Paris, 1888), p. 132.

35. C. Sutto. "Le père Richéome et le nouvel esprit politique des Jésuites français (XVI et XVII ${ }^{e}$ siècles)" in Les Jésuites parmi les hommes aux XVIe et XVII' siècles (Clermont-Ferrand, 1987), pp. 175-184.

36. "De joindre une longue délibération avec un fait pressé, cela lui est mal-aisé: et c'est pourquoi au contraire aux effets de la guerre il est admirable, par ce que le faire et le 
délibérer se rencontrent en un même temps, et qu'à l'un ou à l'autre il apporte toute la présence de son jugement. Mais aux conseils qui ont trait de temps, à la vérité, il a besoin d'être soulagé." M. Hurault. Op. cit., p. 79.

37. "Harangue de Achille de Harlay au sacre du roi à Chartres" (B.N. 18418, fo 273v-274); "Au roi, à son retour du siège d'Amiens le 30 octobre 1597, au Louvres" (B.N., Ms fr. 18417, fo 179-182); A. Arnauld. Plaidoyer pour l'Université de Paris, pp. 39-42.

38. Sur cette cause, voir S. Marion. Plaidoyé sur lequel a été donné contre les Jésuites l'arrêt du 16 octobre 1597 inséré à la fin d'iceluy (Paris, M. Patisson, 1597); L. Richéome. Réponse de René de La Fon pour les religieux de la Compagnie de Jésus. Au Plaidoyé de Simon Marion en l'arrêt donné contre eux le 16 octobre 1597 (Villefranche, G. Grenier, 1599). Sur le tyrannicide, voir R. Mousnier. L'assassinat d'Henri IV (Paris, 1964).

39. Le père Louis Richéome ne s'y trompe pas. Porte-parole officieux de la Compagnie durant toute cette période, il essaie soigneusement de démarquer les Jésuites français des théoriciens du tyrannicide qui, selon lui, n'expriment qu'une opinion personnelle. Il rappelle régulièrement le pardon général accordé par Henri IV à ses anciens ennemis "considérant que tout ce qu'en ont fait vos sujets (durant les guerres civiles) ce n'a été par aucune haine particulière contre votre personne, mais pour le zèle de leur religion." Plainte apologétique au Roi Très-Chrétien de France et de Navarre pour la Compagnie de Jésus (s. 1., 1603), p. 60v.

40 . M. Greengrass. France in the Age of Henri IV (London, 1984), p. 142. Des visées très personnelles pouvaient également motiver certains adversaires des Jésuites. Lers partisans n'avaient pas le monopole de l'égoïsme.

41. Le franc et véritable discours au roi, p. 17.

42. Sur le gallicanisme, voir V. Martin. Le gallicanisme en France et la réforme catholique (Paris, 1919); J. Powis. "Gallican Liberties and the Politics of Later Sixteenth Century," The Historical Journal $(26,1983), 515-530$; C. Sutto. "Tradition et innovation, réalisme et utopie: l'idée gallicane en France à la fin du XVI ${ }^{\mathrm{e}}$ siècle," Renaissance et Réforme/Renaissance and Reformation (VIII, 1986), 278-297; J. H. M. Salmon. "Gallicanism and Anglicanism in the Age of Counter Reformation" in J. H. M. Salmon. Renaisssance and Revolt (Cambridge, 1987), pp. 155-188.

43. M. Turchetti. "'Concorde ou tolérance' de 1562 à 1598," Revue historique (v. 274, 1985), 341-355.

44. Exhortation et remontrance faite d'un commun accord par les Français Catholiques et pacifiques pour la paix in Mémoires de la Ligue, t. 1, p. 132.

45. É. de La Boétie. Mémoire sur la pacification des troubles (Genève, 1983), p. 52; M. de Montaigne. Les essais (Paris, 1978), Livre III, pp. 790-803. Soulignons à propos d'Étienne de La Boétie que, récemment, un historien l'a présenté, en se basant sur De la servitude volontaire, comme un pamphlétaire anti-monarchiste. Ces deux textes s'opposeraient donc, ce qui nous invite à faire de plus amples recherches sur leur auteur. Cf. J.-L. Bourgeon. "La Boétie pamphlétaire," Bibliothèque d'Humanisme et Renaissance $(51,1989), 289-300$. 
46. "Nous avons pris congé du roi et lui avons parlé du règlement des bénéfices. Je lui ai dit fort intelligiblement que le pape nous faisait assez connaître ne vouloir qu'aucune grâce ne fut espérée de lui et qu'il était temps de faire voir clairement qu'il nous était facile se passer de Rome et d'un si mauvais chef qui voulait abolir les anciennes franchises et libertés de l'Église de France et particulièrement ruiner l'état ecclésiastique et le clergé, la plus belle marque de l'état général de ce royaume." "Lettre de A. de Harlay à J. A. de Thou," mars 1593 (B.N., Dupuy 675, F 164).

47. Par exemple, J. Turquant, magistrat à Rennes, se plaint en septembre 1602 au chancelier de Bellièvre qu'il ne peut mener à bien une affaire "si grandes sont les liaisons de parentés, alliances, et le plus souvent d'intérêts d'entre la plus grande part des magistrats et la noblesse." (B.N., Ms fr. 15899, fo 287). Voir R. Harding. Anatomy of a Power Elite: The Provincial Governors of Early Modern France (New Haven, 1978); J. Dewald. The Formation of a Provincial Nobility: The Magistrates of the Parlement of Rouen, 1499-1610 (Princeton, 1980).

48. J. R. Major. Bellièvre, Sully, and the Assembly of Notables of 1596 (Philadelphia, 1974).

49. Utile ét salutaire avis au roi pour bien régner, p. 56.

50. La justice aux pieds du roi pour les parlements de France, p. 33.

51. Utile et salutaire avis au roi pour bien régner, pp. 36-46.

52. A ce sujet, voir J. Delumeau. Rassurer et protéger. Le sentiment de sécurité dans l'Occident d'autrefois (Paris, 1989).

53. Les études récentes sur l'absolutisme abordent peu la période henricienne. Voir R. Bonney. "Absolutism: What's in a Name," French History (1, 1987), 93-117; J. B. Collins. Fiscal Limits of Absolutism: Direct Taxation in early Seventeenth Century France (Berkeley, 1988); D. Hickey. The Coming of Absolutism (Toronto, 1986); W. Beik. Absolutism and Society in Seventeenth-Century France (Cambridge, 1986). Parmi les historiens qui insistent le plus sur le caractère absolutiste d'Henri IV, notons: D. Ranum. Paris in the Age of Absolutism (New York, 1968), pp. 51-67; J. R. Major. Representative Government in Early Modern France (New Haven, 1980), pp. 259-375.

54. G. Coquille. Institution aux droits des Français (Paris, 1607).

55. A. Sanfaçon. "Légendes, histoire et pouvoir à Chartres sous l'Ancien Régime," Revue historique $(279,1988), 337-357$.

56. “Qu'il plaise à Sa Majesté considérer le misérable état de son Royaume, la campagne désolée, les villes sans traffic, la fureur des gens de guerre qui pillent et ravagent plus cruellement la France, a faute de paiements que ne feraient les plus capitaux ennemis." "Remontrances de la cour de parlement présentées au roi faisant sa diète à St. Germain, en mars 1597" (B.N., N.A.F. 8430, fo $485 \mathrm{v}$.

57. Ibid., fo 487. Sur ce débat, voir A. Chamberland. Le conflit de 1597 entre Henri IV et le parlement de Paris (Paris, 1904).

58. "Traité de la Cour de Parlement" (A. N.: U. 928, fo 19). 
59. C. de Seyssel. La monarchie de France (Paris, 1962).

60. “C'est un proverbe ordinaire que la voix du peuple (c'est à dire des gens de bien, et non de la populace) est la voix de Dieu: parce qu'elle parle de choses notoires, de choses qui ont été vues, et en quoi on ne peut mentir." Plaidoyer pour l'Université de Paris contre les Jésuites, p. 38.

61. La justice aux pieds du roi pour les parlements de France, p. 25.

62. Certains font de la consultation des États-Généraux une des lois fondamentakes du royaume: L'Alouette. Des affaires d'État. Des finances, du Prince et de sa noblesse (Metz, 1597), pp. 2 et 41-42.

63. Utile et salutaire avis au roi pour bien régner, p. 34.

64. S. Marion. Plaidoyers (Paris, 1609), pp. 267-269. Pour une critique de l'inefficacité des États-Généraux comparée aux résultats obtenus par le parlement, voir B. de La Roche Flavin. Treize livres des parlements de France (Bordeaux, 1617), p. 7.

65. “C'est cette obéissance entière, parfaite, absolue, qui gagne les batailles, qui dissipe les ennemis, qui avance le mérite et couronne le labeur, sans laquelle rien ne fleurit, rien ne se peut affermir. C'est le vrai lien, l'ornement et la force de toutes choses." Plaidoyer pour l'Université de Paris contre les Jésuites, p. 9.

66. A. Jouanna. Le devoir de révolte (Paris, 1989), pp. 300-312.

67. L. Le Roy. Les politiques d'Aristote (Paris, 1568), p. 517. Pour une approche semblable, voir L. Charondas Le Caron. Pandectes, ou digestes du droit français (Paris, 1637), pp. 117-118.

68. Utile et salutaire avis au roi pour bien régner, p. 6.

69. B. du Haillan. De l'état et succès des affaires de France (Paris, 1609), p. 307.

70. Des bourgeois, tant catholiques que protestants, continueront à la défendre à la fin des guerres de religion. R. Mousnier. "L'opposition politique bourgeoise à la fin du XVIe siècle et au début du XVII ${ }^{\mathrm{e}}$ siècle. L'oeuvre de Louis Turquet de Mayerne," Revue Historique (213, 1955), 1-20.

71. Pour comprendre comment cette obéissance s'est construite, voir J. R. Strayer. "France: The Holy Land, the Chosen People, and the Most Christian King" in Action and Conviction in Early Modern Europe (Princeron, 1969), 3-16.

72. La justice aux pieds du roi pour les parlements de France, p. 12. "Otés aux empires leur justice, aux royaumes leurs légitimes magistrats, vous les privés de vie." B. de La Roche Flavin. Op. cit., p. 286.

73. La justice aux pieds du roi pour les parlements de France, p. 7. Cette idée sera reprise dans B. de La Roche Flavin. Treize livres des parlements de France, p. 689.

74. P. de L'Estoile. Op. cit., t. 7, p. 93. Sur la crise d'Amiens et l'attitude des parlemtaires à cette époque, voir A. Chamberland, Op. cit.

75. J. Bodin. Les six livres de la République (Paris, 1583), p. 632. Sur la définition qu'il donne du sénat romain, voir p. 365. 
76. A ce sujet, voir R. Mousnier. La vénalité des offices sous Henri IV et Louis XIII (Paris, 1971); M. L. Cummings. The Long Robe and the Sceptre (Ph.D. dissertation, University of Colorado, 1974). Le chancelier Pomponne de Bellièvre s'oppose fermement à la Paulette et rédige à ce sujet un mémoire qu'il transmet au roi. Il y affirme entre autres que "le plus hardi acheteur est préféré au plus suffisant et plus homme de bien. Les bonnes loix sont nécessaires, mais les loix sont inutiles s'il n'y a pas un bon magistrat qui les exerce." Ce mémoire se trouve dans la Revue Henri IV (1, 1906), pp. 184-186.

77. Utile et salutaire avis au roi pour bien régner, pp. 26-27.

78. "Lettre de Jean de Thumery à J. A. de Thou” (B.N., Dupuy 802, fo 63).

79. "Qui dit parlementaire, dans la seconde moitié du XVI' siècle, dit plus ou moins anti-monarchiste." J.-L. Bourgeon. "La Fronde parlementaire à la veille de la Saint Barthélémy," Bibliothèque de l'École des Chartes (148, 1990), p. 81.

80. Certains historiens croient que ces conflits mettaient en danger l'existence même de l'État: J. H. Shennan. The Parlement of Paris (Ithaca, 1968), p. 236.

81. J. M. Hayden. France and the Estates General of 1614Y (London, 1973).

82. "Et au lieu qu'ils avaient encore quelque respect à ce nom et à la réputation de notre roi ils parlent avec mépris." "Lettre de J. Gillot à J.A. de Thou" (B.N., Dupuy 819, fo 112). 